\title{
Editorial
}

\section{A new season of Chinese cardiovascular pharmacology research}

\author{
Alex F CHEN ${ }^{1,3}$, Ding-feng SU ${ }^{2,3}$ \\ ${ }^{I}$ Department of Pharmacology and Toxicology, Michigan State University East Lansing, MI 48824-1317, USA; ${ }^{2}$ Department of Pharmacology, \\ Second Military Medical University, Shanghai 200433, China
}

\begin{abstract}
${ }^{3}$ Correspondence to Drs Alex F CHEN and Ding-feng SU.
Dr Alex F CHEN: Phn 1-517-432-2730. Fax 1-517-353-8915. E-mail chenal@msu.edu

Dr Ding-feng SU: Phn 86-21-2507-0323. Fax 86-21-6549-3951. E-mail dfsu@citiz.net
\end{abstract}

Received 2004-12-23

Accepted 2005-01-10

doi: $10.1111 / \mathrm{j} .1745-7254.2005 .00060 . \mathrm{x}$

In this issue of Acta Pharmacologica Sinica, we are proud to present to our readers and colleagues a series of review articles from several Chinese-American university laboratories in $\mathrm{USA}^{[1-6]}$. These reviews are a collection of the proceedings from the 8th Chinese Cardiovascular Pharmacology Conference held on July 23-26, 2004 in Urumchi, Xinjiang. As the first of its kind at any Chinese Pharmacological Society meeting, a half-day research symposium in English was held on the first day of this conference (an official meeting of the society held every three years for Chinese cardiovascular pharmacologists worldwide). The symposium was co-sponsored by the Cardiovascular Pharmacology Division of the Chinese Pharmacological Society and the Academy of Cardiovascular Research Excellence (ACRE), a non-profit academic organization in USA that includes many of prominent American faculties from mainland China in the field of cardiovascular research.

Like many other biomedical research areas in China, cardiovascular pharmacology research has experienced significant growth in recent years. The Cardiovascular Pharmacology Division is the largest division of the Chinese Pharmacological Society with the most registered members. Similarly, of all the original research articles published in Acta Pharmacologica Sinica, the premier pharmacology journal in China, the total number of cardiovascular pharmacology articles currently ranked first. An increasing number of cardiovascular pharmacology laboratories in China have recently begun to publish their original research findings in international journals, including some in the top-tier journals of cardiovascular research in the world ${ }^{[7,8]}$. More and more principal investigators have also developed research collabora- tions with a number of overseas laboratories. The aforementioned phenomena represent a promising trend towards a modernizing era of Chinese cardiovascular pharmacology in the early 21 st century.

Despite the significant progress and growth, biomedical research in China still faces a number of major challenges as highlighted in two unprecedented "China voices" supplements recently published in Nature $\mathrm{e}^{[9,10]}$. Among these problems, a major issue is a lack of impact in scientific publications. Although the total publications from China ranked the ninth in the world between the years 1997-2001, the citations per paper from China ranked only the nineteenth with a rate of 1.56 according to a most recent study based on the ISI Essential Science Indicators ${ }^{[11]}$. A prominent overseas Chinese-American scientist pointed out that as "measured by the number of original research papers published in internationally refereed high-impact journals", a productive scientist should have "published at least eight highly cited research papers in the past ten years ... in a journal with an impact factor of at least two ... and at least one should be published in a journal with an impact factor of five or above"[12]. If such a "not overly demanding standard"[12] would be used to judge research productivity, concrete efforts must be made by a majority of Chinese cardiovascular pharmacologists to meet it.

Chinese pharmacologists worldwide are eager and determined to make a significant contribution to the success of the 15th World Congress of Pharmacology (IUPHAR) to be hosted by the Chinese Pharmacological Society in Beijing on July 2-7, 2006. The primary authors of this review collection all grew up in China and now have all established their 
independent research laboratories in several major universities across the United States. The research work they presented in these reviews spans from molecular cardiovascular biology to integrated physiology and pharmacology. As an internationally refereed pharmacology journal with increasing impact, Acta Pharmacologica Sinica would like to showcase the research of these overseas Chinese cardiovascular pharmacologists in this issue, and by doing so hopes to enhance not only the research exchange and collaboration between Chinese pharmacologists at home and overseas, but also the quality and impact of Chinese pharmacology research in the world.

\section{References}

1 Luo JD, Chen AF. Nitric oxide: a newly discovered function on wound healing. Acta Pharmacol Sin 2005; 26: 259-64.

2 Duan DY, Liu LL, Bozeat N, Huang ZM, Xiang SY, Wang GL, et al. Functional role of anion channels in cardiac diseases. Acta Pharmacol Sin 2005; 26: 265-78.
3 Ren J, Fang CX. Small guanine nucleotide-binding protein Rho and myocardial function. Acta Pharmacol Sin 2005; 26: 279-85.

4 Wang DH. The vanilloid receptor and hypertension. Acta Pharmacol Sin 2005; 26: 286-94.

5 Sun ZJ, Zhang ZE. Historic perspectives and recent advances in major animal models of hypertension. Acta Pharmacol Sin 2005; 26: 295-301.

6 Liao DF, Chen LL, Peng CY, Zhang J, Li K. Exo ${ }^{+}$proofreading polymerases mediate genetic analysis and its application in biomedical studies. Acta Pharmacol Sin 2005; 26: 302-6.

7 Wang GL, Wang XR, Lin MJ, He H, Lan XJ, Guan YY. Deficiency in ClC-3 chloride channels prevents rat aortic smooth muscle cell proliferation. Circ Res 2002; 91: E28-32.

8 Xu FP, Chen MS, Wang YZ, Yi Q, Lin SB, Chen AF, et al. Leptin induces hypertrophy via endothelin-1-reactive oxygen species pathway in cultured neonatal rat cardiomyocytes. Circulation 2004; 110: 1269-75.

9 Poo MM, Wu R, Chiew K, Chien L, Yang X, Wu CI, et al. China: views from the west. China voice I. Nature 2004; 428: 203-22.

10 China voice II. Nature 2004; 432 (Suppl): A5-55.

11 King DA. The scientific impact of nations. Nature 2004; 430: 311-6.

$12 \mathrm{Wu}$ R. Making an impact. Nature 2004; 428: 206-8. 